\title{
Computed Tomography and Magnetic Resonance Imaging Evaluation in Pediatric Unilateral Sensorineural Hearing Loss
}

\author{
Se A Lee, Sang Kuk Lee, Sang Woo Sun, Jae Hyun Jung, Jong Dae Lee*, and Bo Gyung Kim* \\ Department of Otorhinolaryngology-Head and Neck Surgery, Soonchunhyang University College of Medicine, Bucheon, Korea
}

\section{소아 일측성 감각신경성 난청에서 전산화 단층 촬영과 자기공명영상의 영상학적 평가}

이세아 · 이상국 · 선상우 · 정재현 · 이종대" · 김보경*

순천향대학교 의과대학 이비인후과학교실

\author{
Received April 5, 2017 \\ Revised June 5,2017 \\ Accepted June 17, 2017 \\ Address for correspondence \\ Bo Gyung Kim, MD, PhD \\ Department of Otorhinolaryngology- \\ Head and Neck Surgery, \\ Soonchunhyang University \\ College of Medicine, 170 Jomaru-ro, \\ Bucheon 14584, Korea \\ Tel $+82-32-621-6951$ \\ Fax $+82-32-621-5018$ \\ E-mail bgkim@schmc.ac.kr \\ Address for correspondence \\ Jong Dae Lee, MD, PhD \\ Department of Otorhinolaryngology- \\ Head and Neck Surgery, \\ Soonchunhyang University \\ College of Medicine, 170 Jomaru-ro, \\ Bucheon 14584, Korea \\ E-mail1jdent@schmc.ac.kr \\ *These authors contributed equally \\ to this work.
}

Background and Objectives Children with unilateral sensorineural hearing loss (USNHL) are not actively evaluated by physicians. The diagnostic tool for evaluation of USNHL is also controversial, and no strategy for diagnosing USNHL through imaging studies has been established. We examined the results of temporal bone computed tomography (TBCT) imaging and magnetic resonance imaging (MRI) studies on children with USNHL.

Subjects and Method Eighty-nine patients with USNHL were reviewed. Of these patients, 21 underwent both TBCT and MRI, 51 underwent temporal MRI only, and 17 underwent TBCT only.

Results The etiology of USNHL were determined through imaging studies in 20 patients. The most common abnormal finding $(65 \%)$ was a narrow internal auditory canal identified on TBCT and cochlear nerve aplasia on temporal MRI. Incomplete partition $(20 \%)$, common cavity $(10 \%)$, and labyrinthitis ossificans $(5 \%)$ were also observed in imaging studies. The hearing threshold was lower in USNHL patients with normal findings $(76.1 \pm 28.7 \mathrm{~dB})$ than in USNHL patients with abnormal findings on TBCT or temporal MRI $(100.1 \pm 22.3 \mathrm{~dB})$.

Conclusion Cochlear and cochlear nerve abnormalities can be detected through imaging studies in approximately $25 \%$ of patients with USNHL. Therefore, we suggest that children should undergo TBCT when USNHL is confirmed through audiologic evaluation.

Korean J Otorhinolaryngol-Head Neck Surg 2018;61(1):9-14

Key Words Hearing loss · Magnetic resonance imaging - Sensorineural - Temporal bone computed tomography $\cdot$ Unilateral.

\section{Introduction}

Congenital sensorineural hearing loss is one of the most common health concerns, and affects $11 \%$ of children. ${ }^{1)}$ Unilateral sensorineural hearing loss (USNHL) is commonly not recognized until early grade school and affects approximate-

This is an Open Access article distributed under the terms of the Creative Commons Attribution Non-Commercial License (http://creativecommons.org/licenses/by-nc/4.0) which permits unrestricted non-commercial use, distribution, and reproduction in any medium, provided the original work is properly cited. ly $0.1-3 \%$ of children. ${ }^{2,3)}$ USNHL is underestimated because patients with USNHL show normal development in speech and language. ${ }^{4)}$ As a result, they are not evaluated using imaging studies to determine causes of hearing loss and no active intervention occurs.

Recent studies have suggested that children with USNHL have scholastic or behavioral problems in school. ${ }^{5)}$ Lieu reported that school-aged children with USNHL demonstrated worse oral language scores than did their siblings with nor- 
mal hearing. ${ }^{6}$ A meta-analysis of children with unilateral hearing loss revealed them to have lower full-scale and performance intelligence quotient scores than children with normal hearing. ${ }^{7)}$ Thus far, the importance of USNHL has remained uncertain, and the management of patients with USNHL is controversial. ${ }^{8}$ Children with USNHL are not actively evaluated by physicians, and therefore little is known about the potential of imaging studies in determining the etiology of USNHL in children. The diagnostic tool for evaluation of USNHL is also controversial, and no strategy for diagnosing USNHL through imaging studies has been established. Therefore, in this study, we investigated the results of temporal bone computed tomography (TBCT) imaging and magnetic resonance imaging (MRI) studies and the usefulness of imaging studies in assessing children with USNHL.

\section{Subjects and Method}

\section{Subjects}

We retrospectively reviewed the medical records of children under the age of 18 years who visited our tertiary referral otolaryngology department for unilateral hearing loss during the period of August 2007 to October 2015. Inclusion criteria were as follows: 1) Patients aged 18 years or younger with USNHL, 2) unilateral hearing thresholds worse than $25 \mathrm{~dB}$ with no air-bone gap $(<10 \mathrm{~dB}), 3)$ contralateral normal hearing threshold better than $20 \mathrm{~dB}, 4$ ) having undergone TBCT or temporal MRI. A total of 89 patients (52 boys and 37 girls, mean age $10.9 \pm 4.5$ years) with USNHL were included in this study. The demographics of the patients are shown in Table 1. This study was approved by the Institutional Review Board (IRB No. 2017-04-004) of Soonchunhyang University.

\section{Measurement of hearing threshold}

In the three children who were younger than 3 years, the auditory brainstem response (ABR) was measured using a
GSI Audera (MKS Medic, Madison, WI, USA). For ABR testing, a click stimulus was presented at alternate polarities, using earphones. The lowest intensity at which wave $\mathrm{V}$ was recorded was marked as the patient's hearing threshold (nHL). In the 86 children who were older than 3 years, the hearing level was measured using pure tone audiometry to determine the average hearing thresholds. Hearing loss was evaluated based on the average of pure tone audiogram results at 500 , 1000, 2000, and $4000 \mathrm{~Hz}$.

\section{Imaging studies}

The imaging studies were selected according to the doctor's opinion. High-resolution TBCT imaging with a slice thickness of $<1 \mathrm{~mm}$ was used. Temporal bone scanning was performed using the LightSpeed VCT 64-slice scanner (GE Medical Systems, Milwaukee, WI, USA) with the following settings: detector configuration, $2 \times 0.625 \mathrm{~mm}$; slice thickness, $0.625 \mathrm{~mm}$; field of view, $160 \times 160 \mathrm{~mm}$; resolution, 150 $\mathrm{mA}(60 \mathrm{mAs}), 120 \mathrm{kVp}$; reconstruction matrix, $512 \times 512$. Coronal images were reconstructed with a slice thickness of 1.0 $\mathrm{mm}$. The width of the bony cochlear nerve canal (BCNC) was measured at its midportion using calipers. BCNC stenosis was defined as a BCNC diameter of $1.5 \mathrm{~mm}$ or less in TBCT. ${ }^{9)}$

MRI scans were performed on a 3.0T or 1.5T MRI system (Intera Achieva; Philips Medical Systems, Best, Netherlands) using a six-channel sensitivity-encoding head coil. All images were evaluated with a parasagittal 3D-driven equilibrium sequence perpendicular to the internal auditory canal (IAC). A targeted parasagittal scan perpendicular to the long axis of the IAC was obtained with a T2-weighted 3D turbo spin-echo sequence with a driven equilibrium radio frequency reset pulse following routine MRI sequences with spin-echo T1and T2-weighted images. The imaging parameters for the 3D-driven equilibrium sequence were as follows: repetition time/echo time $=1500 / 200 \mathrm{~ms} ; 256$ acquisition $/ 256$ reconstruction; $15-\mathrm{cm}$ field of view; 1.5 -mm section thickness;

Table 1. Characteristics of the study subjects with USNHL according to the imaging modality

\begin{tabular}{lcccc}
\hline \multicolumn{1}{c}{ Group } & TBCT only & Temporal MRI only & TBCT and temporal MRI & p-value \\
\hline Subject No. & 17 & 51 & 21 & $<.001^{*}$ \\
Age (year) & $9.2 \pm 4.6$ & $12.1 \pm 4.1$ & $9.5 \pm 4.9$ & $0.001^{*}$ \\
Age at confirmation (year) & $9.1 \pm 4.8$ & $12.0 \pm 4.0$ & $8.2 \pm 4.2$ & 0.726 \\
Gender, M/F & $11 / 6$ & $28 / 23$ & $13 / 8$ & 0.363 \\
Hearing threshold (dB) & & & $11.5 \pm 8.9$ & 0.195 \\
$\quad$ Normal ear & $10.0 \pm 6.9$ & $6.6 \pm 3.4$ & $81.5 \pm 26.7$ & \\
$\quad$ Diseased ear & $92.9 \pm 31.4$ & $78.2 \pm 28.8$ & & \\
\hline
\end{tabular}

Values are means $\pm S D$. $* p<0.05$. USNHL: unilateral sensorineural hearing loss, TBCT: temporal bone computer tomography, MRI: magnetic resonance image, No.: number, M: male, F: female, SD: standard deviation 
0.75-mm overlap; number of acquisitions $=2$; and acquisition time $<5$ min. The presence of the cochlear nerve was observed on the parasagittal image of the middle of the IAC, using an automatic window-level setting. Cochlear nerve deficiency was considered if the cochlear nerve was not visualized in temporal MRI. All TBCT and temporal MRI results were reviewed by two otorhinolaryngologists, who were blinded to the subjects' information for consistency.

\section{Statistical analysis}

For statistical analysis, we used Origin software (OriginLab, Northampton, MA, USA). Differences of hearing thresholds between two groups (diagnosed etiology and unknown etiology) were evaluated using t-test. Age and hearing thresholds between groups were evaluated using 1-way analysis of variance. Gender and the number of patients with abnormality in imaging studies between groups were evaluated using Chisquare test. To find the optimal cutoff value of hearing threshold for abnormal findings in imaging studies, receiver operating characteristic (ROC) curve analysis was performed. The optimal cutoff was calculated by Youden's index. A $p$-value of $<0.05$ was considered statistically significant.

\section{Results}

Among the 89 children with USNHL, 21 underwent both TBCT and MRI, 51 underwent temporal MRI only, and 17 underwent TBCT only. The characteristics of the patients are shown in Table 1. The hearing threshold of a normal ear was $10.0 \pm 6.9 \mathrm{~dB}$ in patients with TBCT only, $6.6 \pm 3.4 \mathrm{~dB}$ in patients with temporal MRI only, and $11.5 \pm 8.9 \mathrm{~dB}$ in patients with TBCT and temporal MRI. The hearing threshold of a diseased ear was $92.9 \pm 31.4 \mathrm{~dB}$ in patients with TBCT only, $78.2 \pm 28.8 \mathrm{~dB}$ in patients with temporal MRI only, and $81.5 \pm$ $26.7 \mathrm{~dB}$ in patients with TBCT and temporal MRI.

Table 2 lists all of the significant abnormalities identified on CT and MRI studies on patients with USNHL, according to imaging findings. Of the 89 patients, 20 (5 in TBCT only, 9 in TBCT and temporal MRI, 6 in temporal MRI only) showed abnormal findings identified on TBCT or temporal MRI. The most common abnormal finding (13 of 20 patients, 65\%) was a narrow IAC, compared to a normal ear, identified on TBCT, or cochlear nerve aplasia on temporal MRI. Incomplete partition (20\%), common cavity (10\%), and labyrinthitis ossificans $(5 \%)$ were observed.

Among 21 patients who underwent both TBCT and temporal MRI, 9 showed abnormal findings in TBCT or temporal MRI. One patient exhibited an IAC of normal width, identified on TBCT, but the cochlear nerve was not identified on temporal MRI. Re-review of TBCT images indicated a narrow BCNC (Fig. 1). The other patients with cochlear nerve deficiency identified on temporal MRI had abnormal findings without visualization of the BCNC on TBCT. The number of patients who underwent both TBCT and temporal MRI showed high detection rate of abnormality which was statistically significant among three groups $(p=0.012)$.

The number of patients with etiology confirmed using TBCT or temporal MRI was twenty patients. The hearing thresholds between the patients with abnormality and without abnormality were compared. The hearing threshold was $76.1 \pm 28.7 \mathrm{~dB}$ in the USNHL patients with normal findings on TBCT or temporal MRI, and $100.1 \pm 22.3 \mathrm{~dB}$ in the USNHL patients with abnormal findings on TBCT or temporal MRI (Fig. 2). Statistically significant correlation was observed

Table 2. The number of patients with USNHL according to imaging findings

\begin{tabular}{|c|c|c|c|c|}
\hline \multirow{2}{*}{ Group } & \multirow{2}{*}{ TBCT } & \multicolumn{2}{|c|}{ TBCT+temporal MRI } & \multirow{2}{*}{ Temporal MRI } \\
\hline & & TBCT & Temporal MRI & \\
\hline Subject No. & 17 & & 21 & 51 \\
\hline \multicolumn{5}{|l|}{ IAC } \\
\hline Narrow IAC (in TBCT) & 1 & 8 & & \\
\hline Narrow BCNC (in TBCT) & 1 & 1 & & \\
\hline Cochlea nerve hypoplasia/aplasia (in MRI) & & & 9 & 3 \\
\hline Normal & 12 & 12 & 12 & 45 \\
\hline Incomplete partition & 2 & 1 & 1 & 1 \\
\hline Common cavity & 1 & 0 & 0 & 1 \\
\hline SCC dysplasia & 1 & 0 & 0 & 0 \\
\hline Labyrinthitis ossificans & 0 & 0 & 0 & 1 \\
\hline
\end{tabular}

USNHL: unilateral sensorineural hearing loss, TBCT: temporal bone computed tomography, MRI: magnetic resonance imaging, No.: number, IAC: internal auditory canal, BCNC: bony cochlear nerve canal, SCC: semicircular canal dysplasia 
between confirmation of abnormal findings on imaging and the severity of hearing loss based on pure-tone average ( $p<$ $0.001)$. The area under the curve of proposed nomogram was
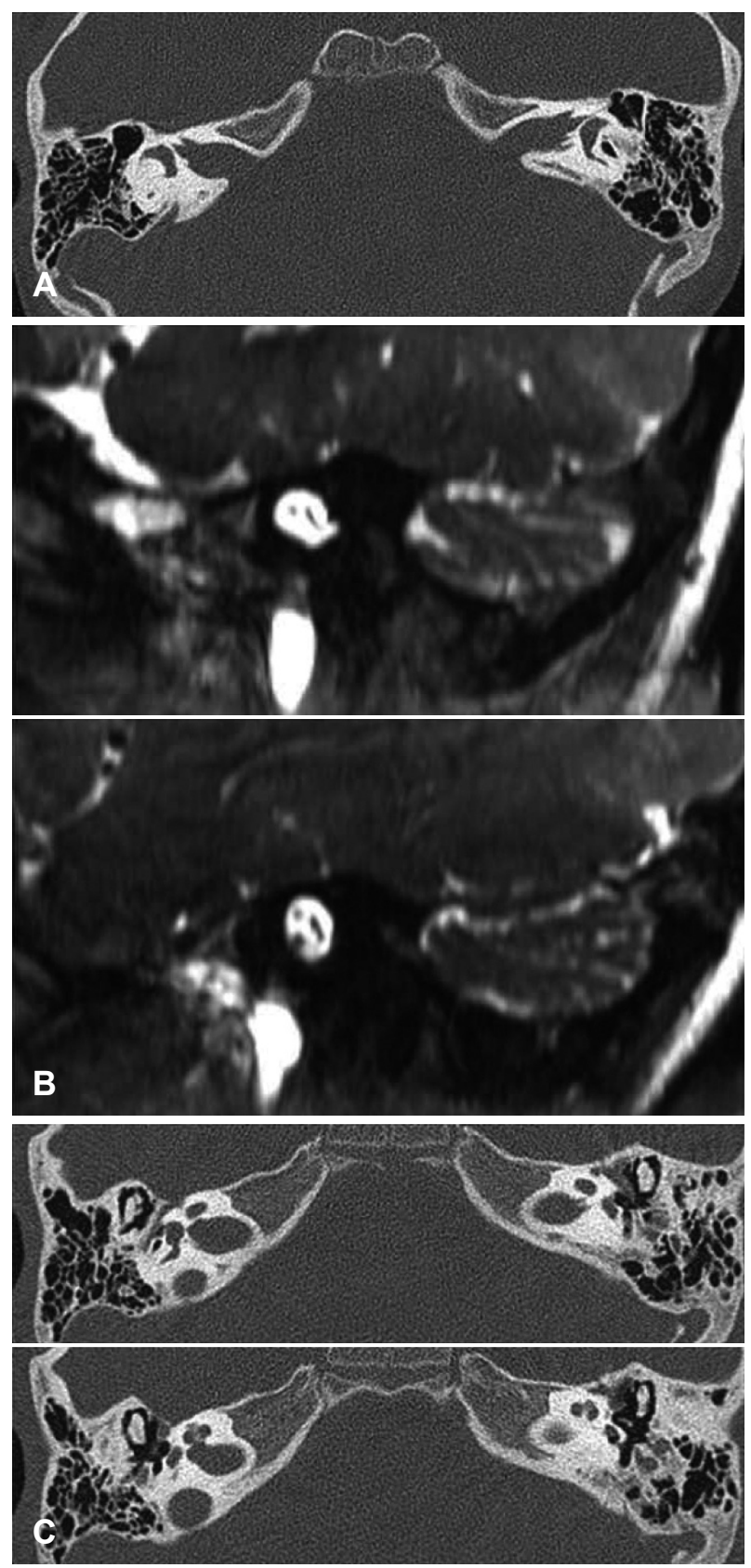

Fig. 1. Imaging findingsofone patient with normal IAC, narrow BCNC identified on temporal bone computer tomography. Normal IAC in bilateral ears (A), cochlear nerve deficiency in diseased ear (upper image) and cochlear nerve present in normal ear (low image) (B), narrow BCNC in diseased ear (left ear, upper image) (C). IAC: internal auditory canal, BCNC: bony cochlear nerve canal.
0.729 by ROC curve analysis, indicating a fair power to identify Hearing threshold. The optimal cut-off value of hearing threshold by the Youden's Index was 101.7 (Table 3).

\section{Discussion}

The present study showed that the overall prevalence of abnormal imaging findings in TBCT or temporal MRI was $22.5 \%$ (20 of 89 patients) in children with USNHL. The prevalence of abnormalities identified by using TBCT was 36.8\% (14 of 38 patients), and the prevalence of abnormalities identified by using MRI was $20.8 \%$ (15 of 72 patients) in children with USNHL. Studies have reported the prevalence of abnormal TBCT findings at 7 to $66.7 \% .^{2,10-12)}$ Simons et al. ${ }^{11)}$ reported that the prevalence of TBCT abnormalities was 35\% (29 of 83 patients), and the prevalence of temporal MRI abnormalities was $25 \%$ (10 of 40 patients) in children with USNHL, which is comparable to the results of our study. Song et al. ${ }^{12)}$ reported that 93 of 322 (28.9\%) children with USNHL were identified as abnormal in TBCT. Masuda reported a relatively high prevalence of inner ear or IAC malformations identified by TBCT in children with USNHL. ${ }^{10)}$

The most common etiology of USNHL in children evaluated through imaging studies was abnormality of the cochlear nerve. Of the 20 patients with abnormal image findings, $13(65 \%)$ exhibited a narrow IAC in the diseased ear, com-

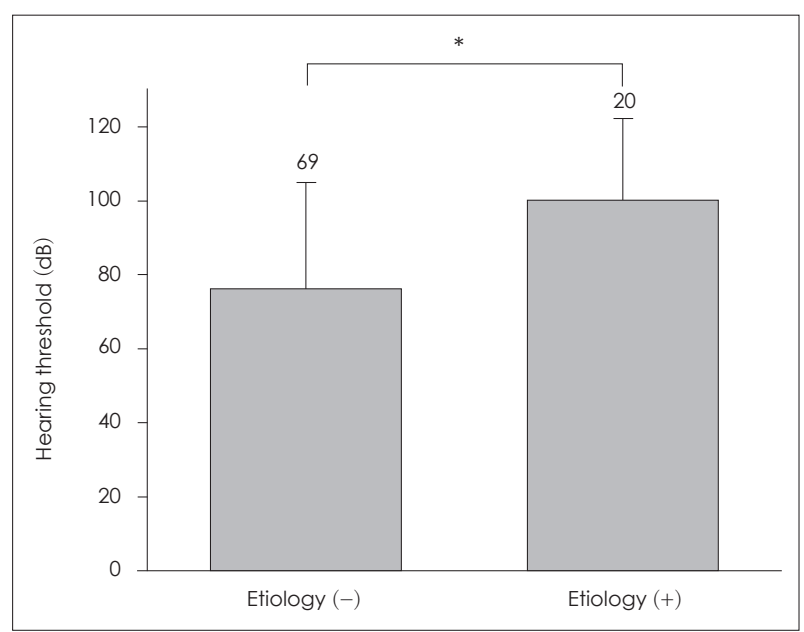

Fig. 2. Difference in hearing levels between patients with etiology confirmed by temporal bone computer tomography or temporal magnetic resonance imaging. ${ }^{*} p<0.05$.

Table 3. Diagnostic performance for abnormal findings in imaging studies

\begin{tabular}{ccccc}
\hline Variable & Threshold* & Sensitivity & Specificity & AUC (95\% Cl) \\
\hline Hearing threshold $(\mathrm{dB})$ & $\geq 101.7$ & $59.10 \%$ & $79.40 \%$ & $0.729(0.617-0.843)$ \\
\hline *threshold was calculated by Youden's Index. AUC: area under the curve, Cl: confidence interval &
\end{tabular}


pared to a normal ear, identified on TBCT, or cochlear nerve deficiency on temporal MRI. Other studies have reported the prevalence of cochlear nerve deficiency at 18 to $73 \%{ }^{13-16)}$ One patient showed discrepancy between normal IAC findings on TBCT and cochlear nerve deficiency on temporal MRI; however, despite the normal IAC finding, TBCT revealed a narrow BCNC. In addition, all the patients who exhibited cochlear nerve deficiency on temporal MRI showed a narrow BCNC on TBCT. Simons et al. ${ }^{11)}$ reported that among 33 patients with USNHL, in 2 cases abnormalities were seen only on MRI, not on TBCT. One of the cases was a hypoplastic eighth nerve, and the other was a brain tumor only identified on MRI. This study has the limitation of not considering the BCNC.

The BCNC is the bone-covered route that passes from the fundus of the IAC to the base of the modiolus. Several studies have investigated the correlation of hearing level and dimensions of BCNC in bilateral/unilateral SNHL. Fatterpekar et al. ${ }^{17)}$ first reported that the length and width of the BCNC were significantly smaller in patients with congenital SNHL than in the control group. Jang et al. ${ }^{18)}$ also reported that the length and width of BCNC in the affected inner ears in USNHL patients were significantly smaller than contralateral inner ears in USNHL patients. In the present study, the patients with cochlear nerve deficiency identified on temporal MRI all exhibited a narrow BCNC on TBCT. This is consistent with recent studies reporting that $\mathrm{BCNC}$ stenosis with a diameter of $1.5 \mathrm{~mm}$ or less, as assessed using CT, suggests cochlear nerve deficiency or hypoplasia, as assessed using MRI. ${ }^{15-19)}$ Our study suggests that if temporal MRI is not performed, a narrow $\mathrm{BCNC}$ finding identified through high resolution TBCT can indicate cochlear nerve deficiency. Adunka et al. ${ }^{20)}$ also suggested that a narrow cochlear aperture can indicate hypoplasia or aplasia of the cochlear nerve.

The present study showed that the children with etiology confirmed by imaging studies had significantly worse hearing levels in the diseased ear. And the cut-off value of hearing threshold for predictive probability for abnormal imaging studies is $101.7 \mathrm{~dB}$ in USNHL. Of the 20 patients with etiology confirmed by imaging studies, 13 exhibited cochlear nerve deficiency, including a narrow BCNC. Definite cochlear nerve deficiency might affect the severity of hearing loss. Wilkins et al. ${ }^{21)}$ showed a significant correlation between the degree of BCNC stenosis and the degree of hearing loss.

The present study showed the high detection rate of abnormality in patients when using temporal bone CT combined with temporal MRI. It's ideal when two imaging studies performed, but high cost and sedation problem cannot be ignored in reality. We suggest that high-resolution TBCT should be performed in patients with USNHL as the initial study. During TBCT, the presence of a narrow BCNC as well as IAC should be checked for cochlear nerve deficiency. The algorithm for patients with USNHL is not established. The central nervous system disorder which is rare can be identified only on temporal MRI. If any neurological symptoms co-occur, MRI should be performed to rule out diseases of the central nervous system. Further investigation should be performed to identify the ideal imaging algorithm (the most effective imaging modality) in these children. Despite the sedation and rehabilitation problems with children, imaging studies in USNHL can yield information that is helpful in counseling patients and parents. Physicians can provide useful information about the etiology of USNHL for almost $26 \%$ of patients, and reassure the parents that USNHL is caused by an inner ear abnormality and determine whether it might affect the contralateral ear. Patients with anatomic abnormalities of the inner ear identified through imaging studies were associated with a higher degree of hearing loss than the patients with unconfirmed etiology.

In conclusion, abnormalities of the cochlea and cochlear nerve can be detected using imaging studies in approximately $25 \%$ of patients with USNHL. TBCT is likely to be adequate as the first imaging modality in all children with USNHL. And BCNC should be checked in TBCT. Therefore, we suggest that children should undergo TBCT after USNHL is confirmed through audiologic evaluation.

\section{Acknowledgments}

This work was supported by the Soonchunhyang University Research Fund.

\section{REFERENCES}

1) Erenberg A, Lemons J, Sia C, Trunkel D, Ziring P. Newborn and infant hearing loss: detection and intervention. American Academy of Pediatrics. Task force on newborn and infant hearing, 1998-1999. Pediatrics 1999;103(2):527-30.

2) Bamiou DE, Savy L, O'Mahoney C, Phelps P, Sirimanna T. Unilateral sensorineural hearing loss and its aetiology in childhood: the contribution of computerised tomography in aetiological diagnosis and management. Int J Pediatr Otorhinolaryngol 1999;51(2):91-9.

3) Bess FH, Dodd-Murphy J, Parker RA. Children with minimal sensorineural hearing loss: prevalence, educational performance, and functional status. Ear Hear 1998;19(5):339-54.

4) Keller WD, Bundy RS. Effects of unilateral hearing loss upon educational achievement. Child Care Health Dev 1980;6(2):93-100.

5) Brookhouser PE, Worthington DW, Kelly WJ. Unilateral hearing loss in children. Laryngoscope 1991;101(12 Pt 1):1264-72. 
6) Lieu JE, Tye-Murray N, Karzon RK, Piccirillo JF. Unilateral hearing loss is associated with worse speech-language scores in children. Pediatrics 2010;125(6):e1348-55.

7) Purcell PL, Shinn JR, Davis GE, Sie KC. Children with unilateral hearing loss may have lower intelligence quotient scores: a metaanalysis. Laryngoscope 2016;126(3):746-54.

8) Kuppler K, Lewis M, Evans AK. A review of unilateral hearing loss and academic performance: is it time to reassess traditional dogmata? Int J Pediatr Otorhinolaryngol 2013;77(5):617-22.

9) Adunka OF, Roush PA, Teagle HF, Brown CJ, Zdanski CJ, Jewells $\mathrm{V}$, et al. Internal auditory canal morphology in children with cochlear nerve deficiency. Otol Neurotol 2006;27(6):793-801.

10) Masuda S, Usui S, Matsunaga T. High prevalence of inner-ear and/ or internal auditory canal malformations in children with unilateral sensorineural hearing loss. Int J Pediatr Otorhinolaryngol 2013;77(2): 228-32.

11) Simons JP, Mandell DL, Arjmand EM. Computed tomography and magnetic resonance imaging in pediatric unilateral and asymmetric sensorineural hearing loss. Arch Otolaryngol Head Neck Surg 2006; 132(2):186-92.

12) Song JJ, Choi HG, Oh SH, Chang SO, Kim CS, Lee JH. Unilateral sensorineural hearing loss in children: the importance of temporal bone computed tomography and audiometric follow-up. Otol Neurotol 2009;30(5):604-8.

13) Laury AM, Casey S, McKay S, Germiller JA. Etiology of unilateral neural hearing loss in children. Int J Pediatr Otorhinolaryngol 2009; 73(3):417-27.
14) McClay JE, Booth TN, Parry DA, Johnson R, Roland P. Evaluation of pediatric sensorineural hearing loss with magnetic resonance imaging. Arch Otolaryngol Head Neck Surg 2008;134(9):945-52.

15) Miyasaka M, Nosaka S, Morimoto N, Taiji H, Masaki H. CT and MR imaging for pediatric cochlear implantation: emphasis on the relationship between the cochlear nerve canal and the cochlear nerve. Pediatr Radiol 2010;40(9):1509-16.

16) Clemmens CS, Guidi J, Caroff A, Cohn SJ, Brant JA, Laury AM, et al. Unilateral cochlear nerve deficiency in children. Otolaryngol Head Neck Surg 2013;149(2):318-25.

17) Fatterpekar GM, Mukherji SK, Alley J, Lin Y, Castillo M. Hypoplasia of the bony canal for the cochlear nerve in patients with congenital sensorineural hearing loss: initial observations. Radiology 2000;215 (1):243-6.

18) Jang JH, Kim JH, Yoo JC, Kim CH, Kim MS, Chang SO, et al. Implication of bony cochlear nerve canal on hearing in patients with congenital unilateral sensorineural hearing loss. Audiol Neurootol 2012;17(5):282-9.

19) Komatsubara $S$, Haruta A, Nagano $Y$, Kodama T. Evaluation of cochlear nerve imaging in severe congenital sensorineural hearing loss. ORL J Otorhinolaryngol Relat Spec 2007;69(3):198-202.

20) Adunka OF, Jewells V, Buchman CA. Value of computed tomography in the evaluation of children with cochlear nerve deficiency. Otol Neurotol 2007;28(5):597-604.

21) Wilkins A, Prabhu SP, Huang L, Ogando PB, Kenna MA. Frequent association of cochlear nerve canal stenosis with pediatric sensorineural hearing loss. Arch Otolaryngol Head Neck Surg 2012;138(4):383-8. 